\title{
Prenatal androgen treatment alters body composition and glucose homeostasis in male rats
}

\author{
Milos Lazic, Fraser Aird, Jon E Levine ${ }^{1}$ and Andrea Dunaif \\ Division of Endocrinology, Metabolism and Molecular Medicine, Northwestern University, Chicago, Illinois 60611, USA \\ ${ }^{1}$ Department of Neurobiology and Physiology, Northwestern University, Evanston, Illinois 60208, USA \\ (Correspondence should be addressed to A Dunaif; Email: a-dunaif@northwestern.edu)
}

\begin{abstract}
Prenatal androgen produces many reproductive and metabolic features of polycystic ovary syndrome in female rodents, sheep, and monkeys. We investigated the impact of such prenatal treatment in adult male rats. Pregnant dams received free testosterone ( $\mathrm{T}$; aromatizable androgen), dihydrotestosterone (D; nonaromatizable androgen), or vehicle control (C) on embryonic days 16-19. Neither of the prenatal androgen treatments resulted in increased body weight from weaning to age 65 days in males. However, at 65 days, there were significant increases in retroperitoneal $(P<0.001 \mathrm{~T}$ versus $\mathrm{C}$; $P<0.05 \mathrm{D}$ versus $\mathrm{C})$, epididymal $(P<0.05 \mathrm{~T}$ versus $\mathrm{C})$, and subcutaneous $(P<0.01 \mathrm{~T}$ versus $\mathrm{C})$ fat pads in prenatally androgenized males. While both androgens altered body composition, subcutaneous fat depots increased only in
\end{abstract}

$\mathrm{T}$ males. $\mathrm{T}$ males had elevated glucose levels $(P<0 \cdot 01)$ compared to $\mathrm{C}$ males. There were no differences among the three groups in insulin sensitivity, circulating lipid and leptin levels, or hepatic triglyceride content. Real-time PCR analysis of insulin signaling pathway genes in retroperitoneal fat revealed a transcriptional downregulation of adipsin and insulin receptor substrate- 1 in $\mathrm{T}$ and $\boldsymbol{\alpha}-1 \mathrm{D}$ adrenergic receptor in $\mathrm{D}$ compared to $\mathrm{C}$ males. We conclude that transient exposure to androgen excess in utero increases body fat in adult male rats. Only $\mathrm{T}$ males exhibit increased circulating glucose levels and subcutaneous fat suggesting that these changes may be mediated by aromatization of androgen to estrogen rather than by direct androgenic actions.

Journal of Endocrinology (2011) 208, 293-300

\section{Introduction}

Polycystic ovary syndrome (PCOS) is a common endocrine disorder that affects $5-10 \%$ of premenopausal women (Ehrmann 2005). Hyperandrogenemia is the cardinal reproductive feature of this syndrome (Legro et al. 1998), whereas insulin resistance is central to the metabolic phenotype (Dunaif 1997). Familial aggregation of PCOS is well documented, suggesting a genetic susceptibility to this disorder (Legro et al. 1998, Urbanek 2007). First-degree female relatives of women with PCOS have an increased prevalence of hyperandrogenemia, insulin resistance, and metabolic syndrome (Sam et al. 2005, 2006). Brothers of women with PCOS have elevated levels of dehydroepiandrosterone sulfate (Legro et al. 2002) and metabolic abnormalities including insulin resistance and dyslipidemia (Yildiz et al. 2003, Yilmaz et al. 2005, Sam et al. 2008). These findings are consistent with the hypothesis that some metabolic and reproductive abnormalities in PCOS are heritable and are not sex specific.

Prenatally androgenized (PA) female nonhuman primates and sheep, two animal models for PCOS, show most of the reproductive and metabolic defects seen in women with
PCOS. Furthermore, we have shown defeminization of the GnRH neurosecretory system (Foecking \& Levine 2005) and increased adiposity, circulating insulin and lipid levels, as well as hepatic triglyceride (TG) content in adult PA female rats (Demissie et al. 2008). These findings suggest that fetal exposure to androgen excess in female rodents programs for both reproductive and metabolic features of PCOS. However, there have been limited investigations of the phenotype of the male offspring in these PCOS animal models. Bruns et al. (2004) showed that adult PA male rhesus monkeys also exhibit insulin resistance and impaired insulin secretion, similar to PA female monkeys. PA male sheep developed oligospermia and reduced sperm motility (Recabarren et al. 2008), while PA male rats showed a decrease in anogenital distance (Wolf et al. 2002). The aim of this study is to determine whether intrauterine androgen excess programs for the metabolic features of PCOS in adult male rats, as has been previously seen in PA female rats. We also seek to determine whether the resulting metabolic phenotype is mediated by the androgenic or estrogenic pathway. These experiments assess the potential link between fetal exposure to androgen excess in males and metabolic features similar to those observed in first-degree male relatives of women with PCOS. 


\section{Materials and Methods}

\section{Animal treatments and diet}

All rodent procedures were approved by the Animal Care and Use Committee at Northwestern University (Evanston, IL, USA). Rats were housed at $23-24^{\circ} \mathrm{C}$ on a $14 \mathrm{~h}$ light: $10 \mathrm{~h}$ darkness cycle.

Time-pregnant female Sprague-Dawley rats were obtained from Charles River (Portage, WI, USA) at day 14 of gestation and treated from embryonic day 16 (E16) to E19 with daily s.c. injections of either $5 \mathrm{mg}$ of an aromatizable androgen testosterone ( $\mathrm{T}, n=6$; T-1500, Sigma), $5 \mathrm{mg}$ of a nonaromatizable androgen $5 \alpha$-dihydrotestosterone (D, $n=7$; Sigma) both dissolved in $500 \mu \mathrm{l}$ sesame oil (S3547, Sigma)/benzyl benzoate (B6630, Sigma) or the vehicle as a control $(\mathrm{C}, n=8)$. This treatment paradigm was designed to mimic in female fetuses the fetal $\mathrm{T}$ surge that is observed in male rats (Foecking \& Levine 2005). The male fetuses were, therefore, exposed to supraphysiologic androgen levels. The $\mathrm{D}$ dose was selected based on our previous finding that $5 \mathrm{mg}$ D produced a similar degree of masculinization of the anogenital distance as $5 \mathrm{mg} \mathrm{T}$ in PA female rats (Foecking et al. 2005). In preliminary experiments, we found no significant differences in either female to male offspring ratio, number of pups per litter, or birth weights between $\mathrm{T}, \mathrm{D}$, or $\mathrm{C}$ animals (unpublished observations). All litters were weaned and males were separated from females at 21 days of age and housed 2-3 per cage, unless otherwise stated. Once weaned, rats were fed regular rat chow diet $(3.30 \mathrm{kcal} / \mathrm{g}$ with $24 \%$ as protein, $4 \%$ as fat by weight; Harlan-Teklad, Madison, WI, USA) and water made available ad libitum. Body weight (BW) was monitored weekly from 14 to 63 days. Food intake was monitored twice a week starting at 21 days (weaning) to 12 weeks in cages with individually housed male rats and their $\mathrm{BW}$ was recorded up to 22 weeks.
Study protocols

At weaning, males were either placed 2-3 per cage $29 \mathrm{C}, 27 \mathrm{~T}$, $32 \mathrm{D}$ ) or individually housed to precisely monitor changes in $\mathrm{BW}$ and food intake (8 C, 8 T, 10 D; Fig. 1). Group-housed adult male rats at $65-70$ days of age $(16 \mathrm{C}, 15 \mathrm{~T}, 16 \mathrm{D})$ were fasted overnight, anesthetized with $\mathrm{CO}_{2}$, weighed, and decapitated. In order to examine insulin signaling, roughly half of the animals in all experimental groups were injected i.p. with $5 \mathrm{U}$ of regular human insulin (NovoNordisk, Princeton, NJ, USA) in $100 \mu \mathrm{l}$ of $0.9 \%$ sodium chloride (Abraxis, Schaumberg, IL, USA), and half were injected with $100 \mu$ of $0.9 \%$ sodium chloride, $10 \mathrm{~min}$ before killing. Liver, adipose tissue depots (retroperitoneal, epididymal, and subcutaneous), and soleus muscles were excised, weighed, frozen, and stored at $-80^{\circ} \mathrm{C}$ for further analyses. Tissues from both saline- and insulin-treated rats were used for analyses of body composition and hepatic TG content (16 C, 15 T, $16 \mathrm{D})$, since the acute administration of insulin would not alter these end points.

\section{Dynamic studies}

Dynamic studies of glucose homeostasis were performed in group-housed adult male rats at 60-65 days of age (16 C, 13 $\mathrm{T}, 18 \mathrm{D})$ with jugular catheters implanted 1 day before testing (Fig. 1). Intraperitoneal glucose tolerance test (IPGTT) was performed after an overnight fast $(\sim 15 \mathrm{~h})$. A baseline blood sample was followed by i.p. injection of $1 \mathrm{~g} / \mathrm{kg} \mathrm{BW}$ dextrose and blood sampling at 2, 5, 10, 15, 30, 60, 90, and $120 \mathrm{~min}$. The baseline blood sample was used to determine the fasting glucose, insulin, C-peptide, leptin, and total cholesterol and TG levels. Intraperitoneal insulin tolerance test (IPITT) was performed after $4 \mathrm{~h}$ of fasting. A baseline blood sample was obtained followed by i.p. injection of $1 \mathrm{U} / \mathrm{kg} \mathrm{BW}$ insulin and blood sampling at 15, 30, 60, 90, and $120 \mathrm{~min}$. Animals were allowed a minimum of $48 \mathrm{~h}$ to recuperate between the IPGTT and IPITT.

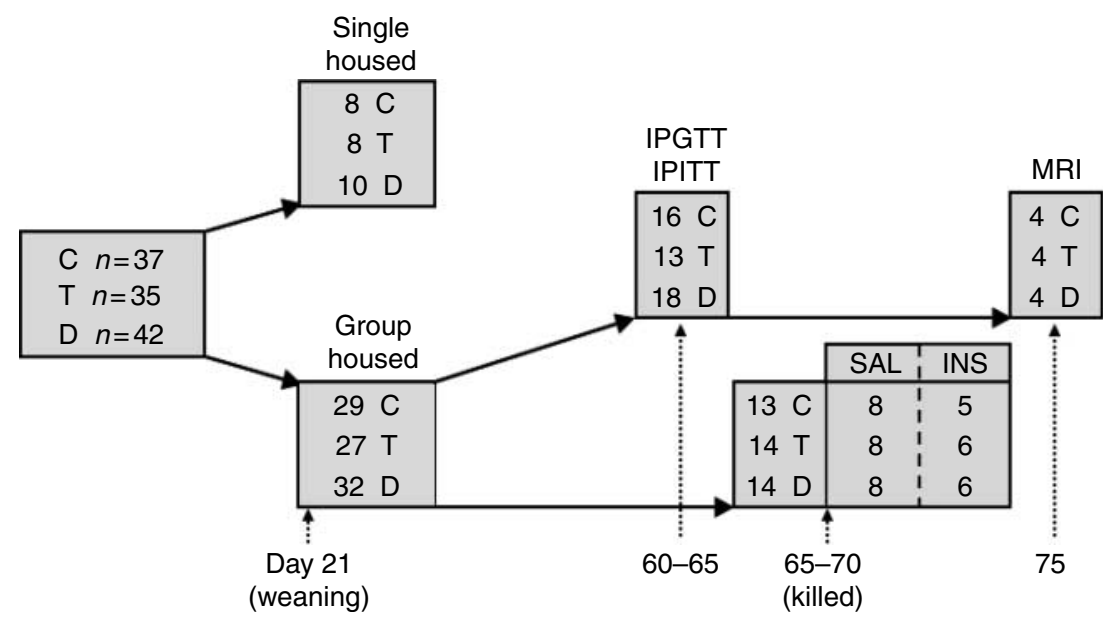

Figure 1 Study schema with the number of animals used in each experiment. IPITT, intraperitoneal insulin tolerance test; IPGTT, intraperitoneal glucose tolerance test; SAL, saline baseline; INS, insulin stimulated; MRI, magnetic resonance imaging. 
Hormone assays, plasma lipids, and hepatic TG content

Whole blood glucose levels were measured using Prestige Smart System Glucose Monitor (Home Diagnostics, Inc., Fort Lauderdale, FL, USA). Insulin and leptin levels were measured by Ultra Sensitive Rat Insulin and Rat Leptin ELISA kits respectively (Crystal Chem, Inc., Downers Grove, IL, USA). C-peptide was measured by Rat C-Peptide I and II ELISA kit (ALPCO Diagnostics, Salem, NH, USA). Circulating TG and cholesterol levels and hepatic TG content were assessed by spectrophotometric assay (Infinity TG and Cholesterol Reagent kits, Thermo Fisher Scientific, Pittsburgh, PA, USA). Circulating free fatty acids (FFA) were measured by the Wako HR series NEFA-HR (2), an in vitro enzymatic colorimetric method assay for the quantitative determination of FFA in serum (Wako Diagnostics, Richmond, VA, USA). Hepatic TG content was expressed as percent of protein content as described previously (Sundaram et al. 2005).

\section{Gene expression profiling}

Total RNA was extracted and purified from $100 \mathrm{mg}$ of retroperitoneal fat ( $n=8$ per group of saline-treated animals) using the RNeasy Lipid Tissue Mini kit (Qiagen). This fat pad was chosen since it was increased in both $\mathrm{T}$ and $\mathrm{D}$ as compared to $\mathrm{C}$ rats and it is also a major visceral fat depot implicated in development of insulin resistance (Gabriely et al. 2002). In all, $1 \mu \mathrm{g}$ of retroperitoneal fat RNA from each rat was reverse transcribed and quantitative real-time PCR (qPCR) analysis of 84 insulin-signaling-pathway-related genes was performed using rat-specific Insulin Signaling RT2 Profiler PCR Arrays (SABiosciences, Frederick, MD, USA) according to the manufacturer's protocol. The complete list of the genes analyzed is available online at http://www.sabiosciences.com/rt_pcr_product/HTML/ PARN-030A.html. Relative gene expression levels were normalized to the average of five housekeeping genes: large ribosomal protein $\mathrm{P} 1$, hypoxanthine phosphoribosyltransferase 1, ribosomal protein L13A, lactate dehydrogenase $\mathrm{A}$, and $\beta$-actin. Data analysis was performed using $\Delta \Delta C_{\mathrm{t}}$-based foldchange method (Livak \& Schmittgen 2001).

\section{Western blotting}

Liver, soleus muscle, and retroperitoneal fat lysates were resolved using SDS-PAGE on $7 \cdot 5 \%$ gels and immunoblotted with specific antibodies to AKT and phospho-AKT (ser473) (Cell Signaling, Beverly, MA, USA), and appropriate secondary antibody (goat anti-rabbit HRP conjugates; Cell Signaling). Retroperitoneal fat lysates $(n=8$ per group of saline-treated animals) were resolved using SDS-PAGE on

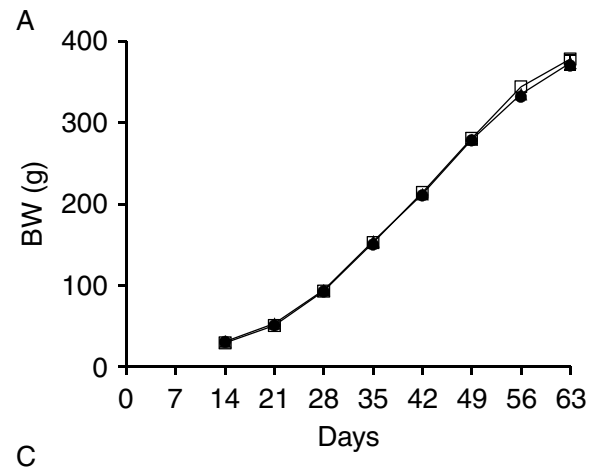

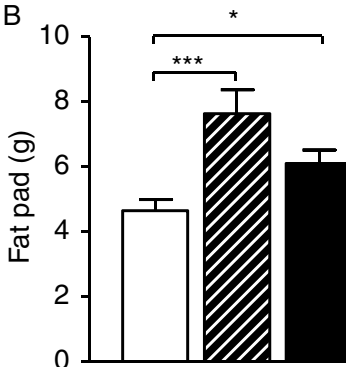

Retroperitoneal

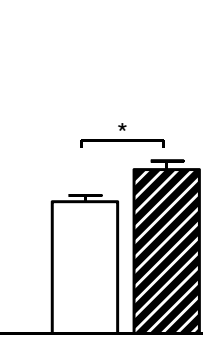

Epididymal

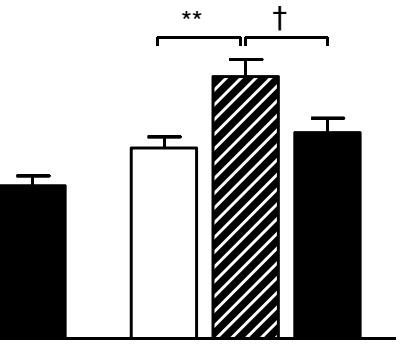

Subcutaneous

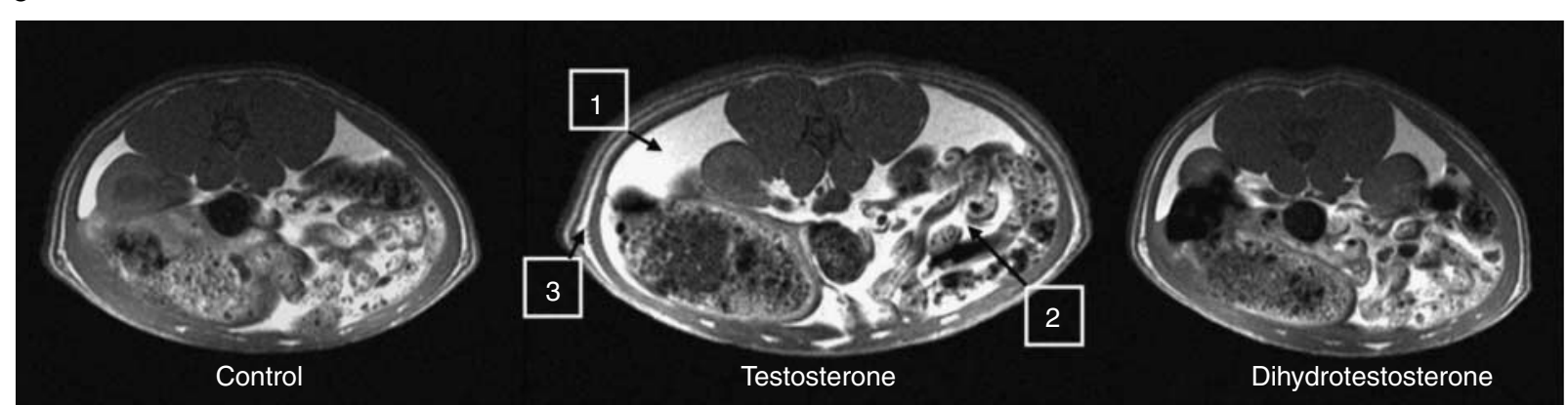

Figure 2 Body weight and body composition. (A) There were no significant differences in BW among control (C; open squares), testosterone (T; black triangles) and dihydrotestosterone (D; black circles) males. (B) Body composition: T males (striped bars) had significantly increased retroperitoneal, epididymal and subcutaneous fat pad weights compared to C males (open bars). D males (black bars) had significantly increased retroperitoneal fat pad weight compared to $\mathrm{C}$ males. Values are mean \pm S.E.M. $\mathrm{C}, n=16 ; \mathrm{T}, n=15 ; \mathrm{D}, n=16 .{ }^{*} P<0 \cdot 05, * * P<0 \cdot 01$, ${ }_{* * *} P<0 \cdot 001$ versus $C$. ${ }^{+} P<0.05$ T versus $D$. (C) Representative MRI axial images of visceral area (renal section) in $C, T$, and $D$ males showed a modest increase in retroperitoneal fat content in $\mathrm{D}$ compared to $\mathrm{C}$ males and a more striking increase in both mesenteric and retroperitoneal fat depots in T compared to C males; (1) retroperitoneal, (2) mesenteric, and (3) subcutaneous fat. 
4-20\% gradient gels and immunoblotted with specific antibodies to adipsin L-21 (Santa Cruz Biotechnology, Santa Cruz, CA, USA), insulin receptor substrate-1 (IRS-1; Millipore Corporation, Billerica, MA, USA) and pan-actin (Cell Signaling), and appropriate secondary antibodies (goat anti-rabbit HRP conjugates for IRS-1 and pan-actin, and rabbit anti-goat HRP conjugates for adipsin; Cell Signaling and Santa Cruz Biotechnology respectively). We did not perform western blot analysis for the $\alpha-1 \mathrm{D}$ adrenergic receptor (ADRA1D) due to the lack of specificity of commercially available antibodies (Jensen et al. 2009). Both treatment groups and vehicle controls were run together on the same gels. Bands were visualized and analyzed as described previously (Corbould et al. 2006), with minor modifications. Immunoblots were quantified using a high-resolution scanner and the density was calculated by ImageJ software (National Institutes of Health, Bethesda, MD, USA). Phosphorylation was expressed as the ratio of phosphorylated to total protein.

Fat distribution by magnetic resonance imaging (MRI)

A 3Twhole body MR scanner and an eight-channel knee coil were used to obtain high-resolution images of the whole body of the rat. Four animals per group (Fig. 1) were scanned at 75 days of age immediately after killing. The knee coil allowed the entire body of the rat to be imaged without having to move the animal but still afforded high signal to noise ratio. The imaging included a standard spin echo anatomic scan, a water suppressed image, and a fat suppressed image. The latter two images were used to mask the standard imaging to automate the analysis. The standard spin echo imaging parameters were repetition time $=500 \mathrm{~ms}$, echo time $=11 \mathrm{~ms}$, field of view $=75 \mathrm{~mm}$, matrix $=256$, slice thickness of $2 \mathrm{~mm}$. The inplane resolution was $0.29 \mathrm{~mm}$. With two averages the total acquisition time was $3.2 \mathrm{~min}$. This technique allowed us to gain axial images of visceral area and thus support our fat pad dissection data.

\section{Statistical analysis}

Repeated measures two-way ANOVA with time and treatment as factors was applied to BW and IPITT with a Bonferroni's post hoc test to determine which groups differed significantly. The area-under-the curve for insulin and
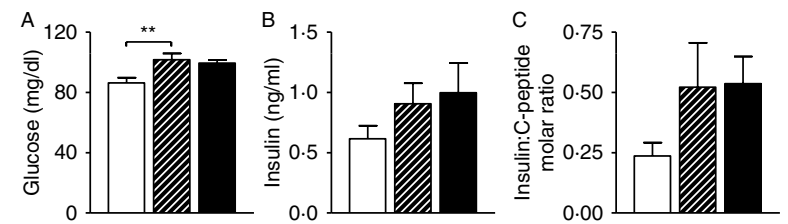

Figure 3 Biochemical changes. (A) Serum glucose levels were significantly increased in $\mathrm{T}$ (striped bars) compared to $\mathrm{C}$ males (open bars), ${ }^{* *} P<0 \cdot 01$ versus C. (B) Serum insulin levels and (C) insulin to $C$-peptide molar ratio were not significantly different among $\mathrm{C}, \mathrm{T}$, and $\mathrm{D}$ males (black bars). Values are mean \pm s.E.M. C, $n=17 ; \mathrm{T}, n=14 ; \mathrm{D}, n=19$.
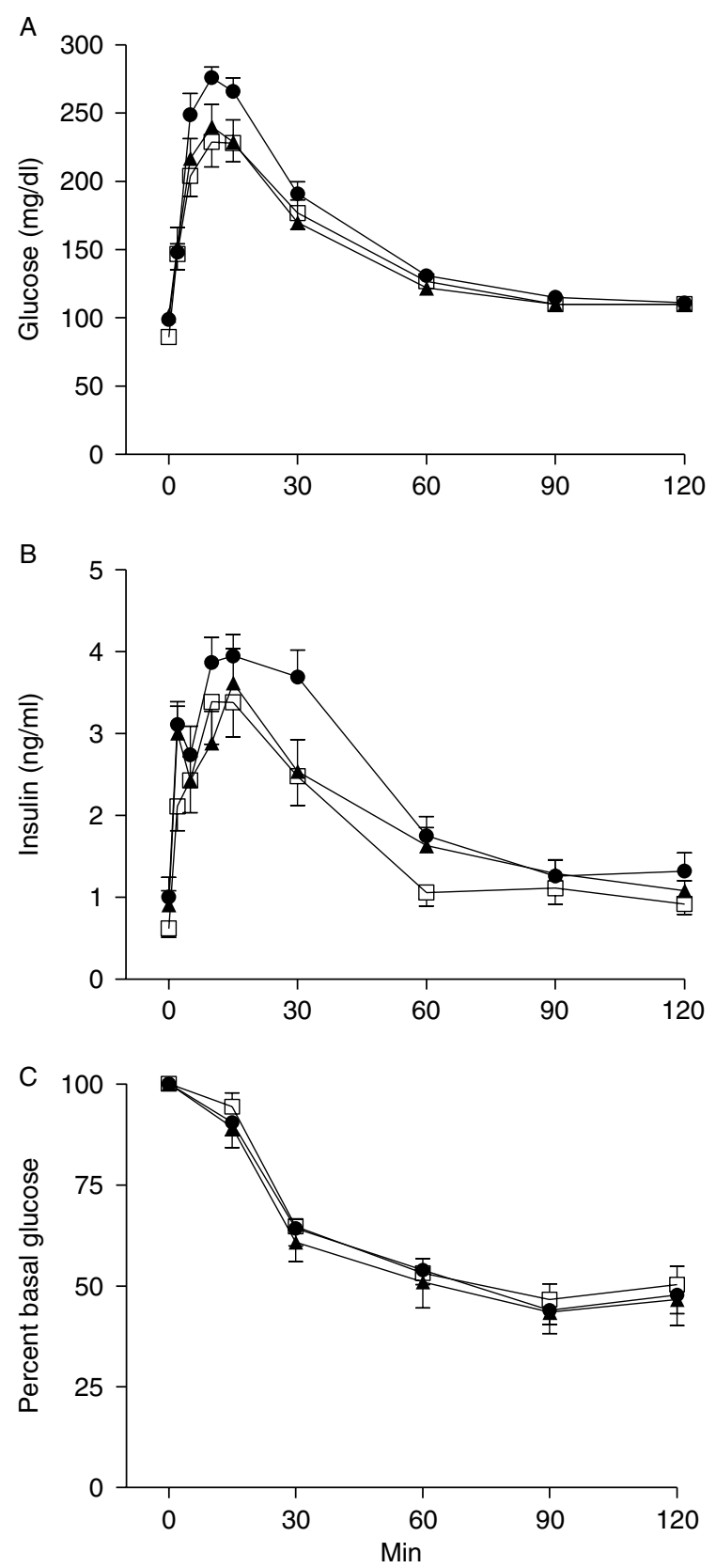

Figure 4 Dynamic testing. There were no significant differences in (A) glucose and (B) insulin levels during IPGTT; (C) percent basal glucose during IPITT among $\mathrm{C}$ (open squares), $\mathrm{T}$ (black triangles), and $D$ males (black circles). Values are mean \pm s.E.M. C, $n=16$; $\mathrm{T}, n=13 ; \mathrm{D}, n=18$.

glucose levels during the IPGTT was determined according to the trapezoidal rule. For all other analyses, one-way ANOVA with Tukey's or the Kruskal-Wallis with Dunn's post hoc test was used according to normality of the data. Data are reported as mean \pm s.E.M. with significance at $P<0 \cdot 05$. All analyses were performed using GraphPad Software (GraphPad Software, Inc., San Diego, CA, USA). 


\section{Results}

\section{Baseline features}

There were no differences in BW days 14-63 among prenatal $\mathrm{T}, \mathrm{D}$, and $\mathrm{C}$ group-housed males (Fig. 2A). There were also no differences among $\mathrm{T}, \mathrm{D}$, and $\mathrm{C}$ males in food intake (up to 12 weeks) or BW (up to 22 weeks) of age in individually housed males (data not shown). However, at 65-70 days, the retroperitoneal fat depots were increased by almost $60 \%$ in $\mathrm{T}$ compared to $\mathrm{C}$ males $(P<0 \cdot 001)$ and $30 \%$ in D compared to $\mathrm{C}$ males $(P<0 \cdot 05$; Fig. $2 \mathrm{~B})$. Both epididymal $(P<0 \cdot 05)$ and subcutaneous fat $(P<0 \cdot 01)$ were increased $(20-30 \%)$ in $\mathrm{T}$ compared to $\mathrm{C}$ males. Subcutaneous fat depots were increased only in $\mathrm{T}$ males $(P<0 \cdot 05, \quad \mathrm{~T}$ versus $\mathrm{D}$; Fig. $2 \mathrm{~B})$. Representative axial MRI images of the visceral area (renal section) show a modest increase in retroperitoneal fat content in $\mathrm{D}$ compared to $\mathrm{C}$ males and a more striking increase in both mesenteric and retroperitoneal fat depots in $\mathrm{T}$ compared to $\mathrm{C}$ males (Fig. 2C).

$\mathrm{T}$ males had elevated fasting glucose levels $(P<0 \cdot 01)$ compared to $\mathrm{C}$ males, but there was no significant difference in circulating insulin levels among the $\mathrm{T}, \mathrm{D}$, and $\mathrm{C}$ males (Fig. 3). There were no significant differences in the insulin to C-peptide molar ratio (Fig. 3) or in circulating C-peptide or leptin levels (not shown). There were also no differences in TG, cholesterol, or FFA levels or in hepatic TG content (not shown).

\section{Dynamic testing}

Following IPGTT, there were no differences in glucose or insulin responses among T, D, and C males (Fig. 4). There were no differences in insulin sensitivity assessed by IPITT among T, D, and C males (Fig. 4).

\section{Insulin signaling}

There were no significant differences in insulin-stimulated activation of AKT (phospho-AKT to AKT ratio) in the soleus muscle, liver, or retroperitoneal fat pads among T, D, and $\mathrm{C}$ males (Fig. 5). Analysis of insulin signaling pathway genes in retroperitoneal fat by qPCR revealed a significant downregulation of adipsin/complement factor $\mathrm{D}(A d n / C f d)$ and Irs-1 mRNA levels in $\mathrm{T}$ males, and Adra1d mRNA levels in D compared to C males (Table 1). A trend was observed in IRS-1 protein abundance in retroperitoneal fat, expressed as percent standard and normalized to pan-actin levels: $122 \pm 12$ in $\mathrm{C}, 67 \pm 18$ in $\mathrm{T}$, and $87 \pm 17$ in $\mathrm{D}$ males (mean \pm s.E.M., one-way ANOVA, $P=0 \cdot 12$, not shown). There were no significant differences detected in total protein abundance of adipsin normalized to pan-actin levels in retroperitoneal fat pads among $\mathrm{T}, \mathrm{D}$, and $\mathrm{C}$ males (not shown).

\section{Discussion}

We have previously reported that prenatal androgen excess programs for features of the metabolic syndrome in adult female rats (Demissie et al. 2008). This study reveals that prenatal androgen excess programs male rat offspring for increased body fat mass and fasting glucose levels in early adulthood, although there were no changes in total BW. In particular, at 65 days of age, prenatal $\mathrm{T}$ treatment significantly increased both visceral (retroperitoneal and epididymal) and subcutaneous fat depots, while prenatal D treatment increased
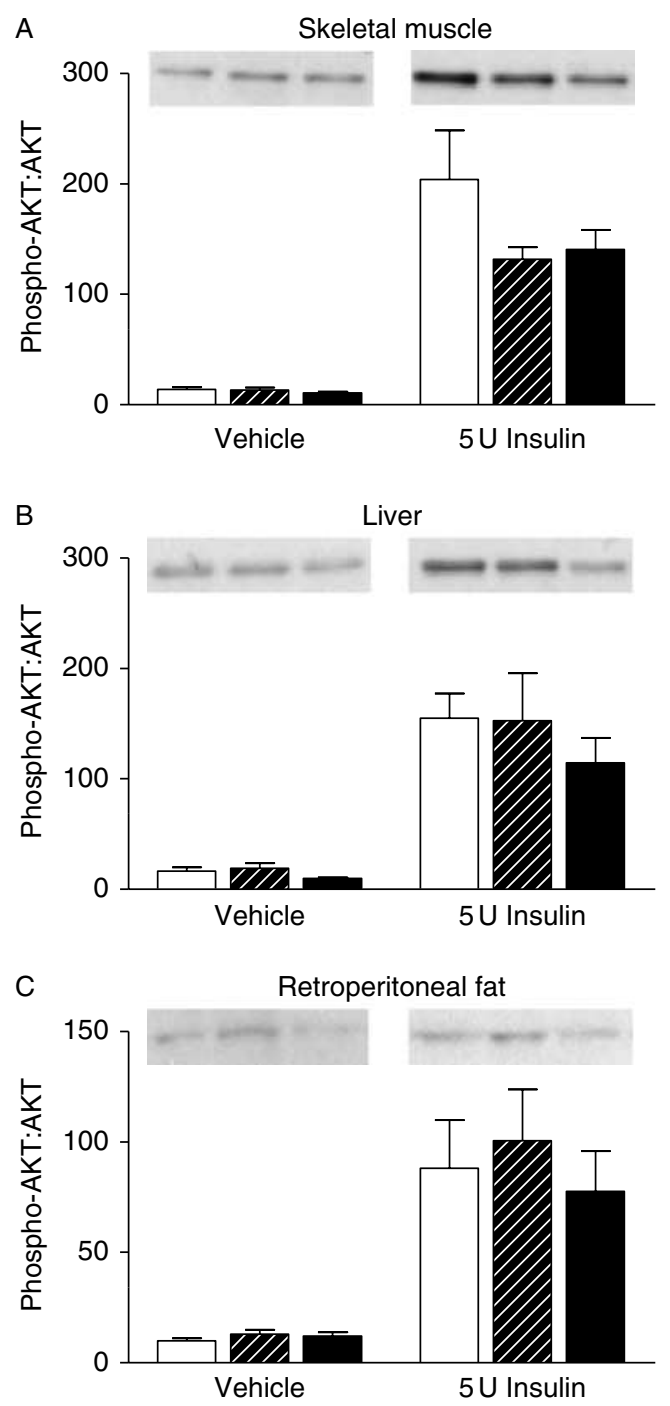

Figure 5 Insulin signaling (represented as a phospho-AKT:AKT ratio) after $10 \mathrm{~min} \pm$ i.p. insulin $(5 \mathrm{U})$. No differences in insulin action were detected in (A) the skeletal muscle, (B) the liver, and (C) retroperitoneal fat among $\mathrm{C}$ (open bars), $\mathrm{T}$ (striped bars), and $\mathrm{D}$ males (black bars). Tissue-specific representative western blot images of phospho-AKT are shown above the figures. Values are mean \pm s.E.M. C, $n=8$ saline, $n=5$ insulin; T, $n=8$ saline, $n=6$ insulin; $\mathrm{D}, n=8$ saline, $n=6$ insulin. 
Table 1 Expression profiling of insulin-signaling-pathway-related genes in retroperitoneal fat of male rats. Values are means \pm s.E.M.

\begin{tabular}{|c|c|c|c|c|c|}
\hline \multirow{2}{*}{ Group } & C & $\mathbf{T}$ & D & \multirow{2}{*}{$\begin{array}{c}\text { One-way ANOVA } \\
(P \text { value })\end{array}$} & \multirow{2}{*}{ Gene description } \\
\hline & \multicolumn{3}{|c|}{ Fold difference, \% (normalized to C) } & & \\
\hline \multirow{3}{*}{$\begin{array}{l}\text { Gene } \\
\text { Adn/Cfd } \\
\text { Adra1d } \\
\text { Irs-1 }\end{array}$} & & & & & \\
\hline & $100 \cdot 0 \pm 14 \cdot 3$ & $77 \cdot 9 \pm 13 \cdot 6$ & $59 \cdot 7 \pm 11 \cdot 0^{*}$ & $0 \cdot 04$ & Adrenergic, $\alpha$-1D-, receptor (PI3K pathway) \\
\hline & $100 \cdot 0 \pm 12 \cdot 9$ & $52 \cdot 8 \pm 7 \cdot 8^{*}$ & $69 \cdot 7 \pm 12 \cdot 3$ & $0 \cdot 03$ & Insulin receptor substrate-1 (insulin receptor-associated protein) \\
\hline
\end{tabular}

$n=7-8$ /group, expressed as percent fold-change from controls. ${ }^{*} P<0 \cdot 05, * * P<0 \cdot 01$ versus $C$.

only retroperitoneal fat depots compared to $\mathrm{C}$ males. Circulating glucose levels were significantly increased and Irs-1 mRNA expression was significantly decreased in retroperitoneal fat in $\mathrm{T}$ males. Nevertheless, in both $\mathrm{T}$ and $\mathrm{D}$ males, there were no defects in glucose tolerance, insulin sensitivity, or insulin-mediated activation of AKT in the soleus muscle, liver, or retroperitoneal fat. Furthermore, there were no changes in circulating lipid, FFA, or leptin levels or in hepatic TG content with either PA treatment. These finding are in contrast to those in PA male nonhuman primates that exhibit both insulin resistance and impaired insulin secretion, while maintaining normal fasting serum glucose (Bruns et al. 2004).

Despite significantly increased fat mass, PA male rat total BW did not change, analogous to findings in PA male monkeys (Bruns et al. 2004). These findings suggest that PA alters body composition but not BW in male rats. In contrast, total BW as well as visceral and subcutaneous fat mass increased in PA females (Demissie et al. 2008). In addition, PA females developed increased serum insulin, TG, and cholesterol levels and hepatic TG content (Demissie et al. 2008), whereas T males developed increased fasting glucose levels. Furthermore, despite the marked increase in adipose tissue in PA males, there were no changes in leptin or FFA levels. We failed to detect significant decreases in insulin sensitivity or signaling in PA rats of both sexes. The maintenance of normal circulating glucose levels, despite increased circulating insulin levels, suggested the presence of insulin resistance in PA females (Demissie et al. 2008).

To gain further insight into the mechanism of the programming actions of prenatal androgens in males, we compared the effects of prenatal $\mathrm{D}$ to those of prenatal $\mathrm{T}$. $\mathrm{T}$ can be converted to estrogen by the action of the aromatase enzyme, which, in humans, is expressed in many tissues, including the gonads, central nervous system, bone, placenta, and fetal liver (Mendelson \& Kamat 2007). However, in most vertebrates, including rodents, the primary source of aromatase is the ovary (Mendelson \& Kamat 2007). Therefore, in T-treated animals, reprogramming of fetal tissues could result from exposure to excess estrogen via the dam's gonadal or fetal aromatization of androgens. Thus, the effect of prenatal $\mathrm{T}$ could be due to androgenic and estrogenic pathways. In contrast, D is a nonaromatizable androgen, which has conventionally been thought to signal only through androgenic pathways (McGuire et al. 1960). More recently, it has been shown that a metabolite of $D$, $5 \alpha$-androstan-3 $\beta, 17 \beta$-diol, may activate the estrogen receptors in rat prostate (Weihua et al. 2001) and hypothalamus (Pak et al. 2005). However, other studies do not confirm the findings in the hypothalamus (Lindzey et al. 1998). Furthermore, the amount of $5 \alpha$-androstan$3 \beta, 17 \beta$-diol produced in vivo is small and its circulating half-life is very short (Grover \& Odell 1975). Therefore, it remains likely that the changes observed with prenatal D treatment reflect primarily androgenic actions.

The body composition data and MRI axial images of the visceral area suggest that $\mathrm{T}$ males had increased fat mass compared to both $\mathrm{C}$ and $\mathrm{D}$ males. In particular, subcutaneous fat mass was significantly higher in $\mathrm{T}$ males when compared to both $\mathrm{C}$ and D males. It is well documented that females, both humans and rodents, have a greater amount of subcutaneous fat distributed in the gluteal/femoral region, while males have a more central accumulation of fat (Bjorntorp 1991, Lonnqvist et al. 1997, Clegg et al. 2006). Vague (1956) was first to observe that the pattern of fat deposition in obese individuals might be influenced by relative amounts of androgenic and estrogenic sex hormones. Accordingly, it has been shown that estrogen excess in male rats produces a female-like fat distribution phenotype with increased subcutaneous compared to visceral fat deposition (Clegg et al. 2006). The finding of increased subcutaneous fat depots in $\mathrm{T}$ males suggests that a portion of prenatal Twas aromatized to estrogen and programmed a more female-like body fat distribution. Conversely, prenatal D programmed for increased retroperitoneal fat without changes in subcutaneous fat. This finding is consistent with the observation that androgen receptor density is about two times lower in subcutaneous as compared to visceral fat preadipocytes (Dieudonne et al. 1998), which would decrease the effects of androgens on subcutaneous adipose tissue.

In order to further delineate the mechanisms leading to the differences in body composition in PA males, we performed expression profiling of insulin signaling pathway genes in retroperitoneal fat. This fat depot was chosen since it was increased in both $\mathrm{T}$ and $\mathrm{D}$ males. It is also a major visceral fat pad implicated in development of insulin resistance (Barzilai et al. 1998, Gabriely et al. 2002). We found significant downregulation of $A d n$ and Irs-1 mRNA levels in T and $A d r a 1 d$ mRNA levels in D males. $A d n$, also known as complement factor $\mathrm{D}$, is a serine protease, which stimulates 
glucose transport for TG accumulation in fat cells, inhibits lipolysis, and is involved in the alternative complement pathway (Ronti et al. 2006). Interestingly, another complement factor $-C 3$, closely related to $A d n$ and associated with insulin resistance, is downregulated by neonatal estrogen excess in rats (Alexanderson et al. 2009).

Sex steroids play an important and complex role in preadipocyte differentiation and proliferation. Moreover, IRS-1 has been shown to have a pivotal role in adipocyte differentiation through the activation of proliferator-activated receptor $\gamma$ (Miki et al. 2001). These observations raise the possibility that the elevation in prenatal androgens caused an alteration in IRS-1 expression, which, in turn, programmed for increased adiposity in adulthood. However, Dieudonne et al. (2000) showed that $\mathrm{T}$ reduced the differentiation of preadipocytes extracted from the epididymal tissue of male rats in a dose-dependent manner, suggesting that androgens have a primarily antiadipogenic role on visceral fat depots in the adult. This observation is in contrast to the in vivo effects of androgens on preadipocytes and adipose tissue development. Castrated male rats display a significant decrease in visceral fat depots (Clegg et al. 2006), while PA first-calf heifers had greater fat deposition and increased overall growth rates (Reiling et al. 1997). In agreement with our studies, these observations suggest that androgens exhibit proadipogenic effects in vivo at both pre- and postnatal stages. It is also possible that reduced expression of Adra1d in D males decreased the rates of lipolysis (Lafontan \& Berlan 1993), resulting in increased deposition of fat (Jocken \& Blaak 2008). Contrary to our expectations, there were no changes in the expression levels of genes directly involved in fatty acid metabolism or in lipid/glucose transport, such as acetyl-CoA carboxylase, fatty acid synthase, glucose transporter type 4 , or low-density lipoprotein receptor.

In concordance with the qPCR data, IRS-1 protein in retroperitoneal fat showed a trend for lower levels in $\mathrm{T}$ males as compared to $\mathrm{C}$ males. However, changes in neither IRS-1 nor adipsin protein abundance reached statistical significance. This finding may reflect the fact that the limited number of available samples did not provide adequate statistical power. Furthermore, a lack of correlation between mRNA expression and protein abundance is frequently observed in complex biological systems, often due to the differences in translational efficiency, posttranscriptional regulation of gene expression, and protein stability (Maier et al. 2009). Nevertheless, even in the absence of detectable changes in protein abundance, the observed changes in mRNA levels suggest that prenatal androgens may program for altered transcriptional regulation of these genes. We did not perform western blot analysis for ADRA1D due to the lack of specificity of commercially available antibodies (Jensen et al. 2009).

We conclude that transient exposure to androgen excess in utero increases body fat levels in adult male rats. Only $\mathrm{T}$ males exhibit increased circulating glucose and subcutaneous fat, suggesting that these changes may be mediated by aromatization of androgen to estrogen rather than by direct androgenic actions. In contrast to PA female rats, PA males do not develop insulin resistance or dyslipidemia. These differences suggest that prenatal programing of some metabolic traits by androgens is sex specific.

\section{Declaration of interest}

The authors declare that there is no conflict of interest that could be perceived as prejudicing the impartiality of the research reported.

\section{Funding}

This work was supported by the NIH grant P50 HD044405.

\section{Acknowledgements}

We thank Jorie Aardema, Brigitte Mann, and Jennifer Taylor for technical assistance.

\section{References}

Alexanderson C, Eriksson E, Stener-Victorin E, Lonn M \& Holmang A 2009 Early postnatal oestradiol exposure causes insulin resistance and signs of inflammation in circulation and skeletal muscle. Journal of Endocrinology 201 49-58. (doi:10.1677/JOE-08-0534)

Barzilai N, Banerjee S, Hawkins M, Chen W \& Rossetti L 1998 Caloric restriction reverses hepatic insulin resistance in aging rats by decreasing visceral fat. Journal of Clinical Investigation 101 1353-1361. (doi:10.1172/ JCI485)

Bjorntorp P 1991 Adipose tissue distribution and function. International Journal of Obesity 15 (Supplement 2) 67-81.

Bruns CM, Baum ST, Colman RJ, Eisner JR, Kemnitz JW, Weindruch R \& Abbott DH 2004 Insulin resistance and impaired insulin secretion in prenatally androgenized male rhesus monkeys. Journal of Clinical Endocrinology and Metabolism 89 6218-6223. (doi:10.1210/jc.2004-0918)

Clegg DJ, Brown LM, Woods SC \& Benoit SC 2006 Gonadal hormones determine sensitivity to central leptin and insulin. Diabetes 55 978-987. (doi:10.2337/diabetes.55.04.06.db05-1339)

Corbould A, Zhao H, Mirzoeva S, Aird F \& Dunaif A 2006 Enhanced mitogenic signaling in skeletal muscle of women with polycystic ovary syndrome. Diabetes 55 751-759. (doi:10.2337/diabetes.55.03.06. db05-0453)

Demissie M, Lazic M, Foecking EM, Aird F, Dunaif A \& Levine JE 2008 Transient prenatal androgen exposure produces metabolic syndrome in adult female rats. American Journal of Physiology. Endocrinology and Metabolism 295 E262-E268. (doi:10.1152/ajpendo.90208.2008)

Dieudonne MN, Pecquery R, Boumediene A, Leneveu MC \& Giudicelli Y 1998 Androgen receptors in human preadipocytes and adipocytes: regional specificities and regulation by sex steroids. American Journal of Physiology 274 C1645-C1652.

Dieudonne MN, Pecquery R, Leneveu MC \& Giudicelli Y 2000 Opposite effects of androgens and estrogens on adipogenesis in rat preadipocytes: evidence for sex and site-related specificities and possible involvement of insulin-like growth factor 1 receptor and peroxisome proliferator-activated receptor $\gamma 2$. Endocrinology 141 649-656. (doi:10.1210/en.141.2.649)

Dunaif A 1997 Insulin resistance and the polycystic ovary syndrome: mechanism and implications for pathogenesis. Endocrine Reviews 18 774-800. (doi:10.1210/er.18.6.774)

Ehrmann DA 2005 Polycystic ovary syndrome. New England Journal of Medicine 352 1223-1236. (doi:10.1056/NEJMra041536) 
Foecking EM \& Levine JE 2005 Effects of experimental hyperandrogenemia on the female rat reproductive axis: suppression of progesterone-receptor messenger RNA expression in the brain and blockade of luteinizing hormone surges. Gender Medicine 2 155-165. (doi:10.1016/S15508579(05)80044-0)

Foecking EM, Szabo M, Schwartz NB \& Levine JE 2005 Neuroendocrine consequences of prenatal androgen exposure in the female rat: absence of luteinizing hormone surges, suppression of progesterone receptor gene expression, and acceleration of the gonadotropin-releasing hormone pulse generator. Biology of Reproduction 72 1475-1483. (doi:10.1095/biolreprod. 105.039800)

Gabriely I, Ma XH, Yang XM, Atzmon G, Rajala MW, Berg AH, Scherer P, Rossetti L \& Barzilai N 2002 Removal of visceral fat prevents insulin resistance and glucose intolerance of aging: an adipokine-mediated process? Diabetes 51 2951-2958. (doi:10.2337/diabetes.51.10.2951)

Grover PK \& Odell WD 1975 Correlation of in vivo and in vitro activities of some naturally occurring androgens using a radioreceptor assay for $5 \alpha$-dihydrotestosterone with rat prostate cytosol receptor protein. Journal of Steroid Biochemistry 6 1373-1379. (doi:10.1016/0022-4731(75)90072-2)

Jensen BC, Swigart PM \& Simpson PC 2009 Ten commercial antibodies for $\alpha-1$-adrenergic receptor subtypes are nonspecific. Naunyn-Schmiedeberg's Archives of Pharmacology 379 409-412. (doi:10.1007/s00210-008-0368-6)

Jocken JW \& Blaak EE 2008 Catecholamine-induced lipolysis in adipose tissue and skeletal muscle in obesity. Physiology and Behavior 94 219-230. (doi:10.1016/j.physbeh.2008.01.002)

Lafontan M \& Berlan M 1993 Fat cell adrenergic receptors and the control of white and brown fat cell function. Journal of Lipid Research 34 1057-1091.

Legro RS, Driscoll D, Strauss JF III, Fox J \& Dunaif A 1998 Evidence for a genetic basis for hyperandrogenemia in polycystic ovary syndrome. PNAS 95 14956-14960. (doi:10.1073/pnas.95.25.14956)

Legro RS, Kunselman AR, Demers L, Wang SC, Bentley-Lewis R \& Dunaif A 2002 Elevated dehydroepiandrosterone sulfate levels as the reproductive phenotype in the brothers of women with polycystic ovary syndrome. Journal of Clinical Endocrinology and Metabolism 87 2134-2138. (doi:10.1210/jc.87.5.2134)

Lindzey J, Wetsel WC, Couse JF, Stoker T, Cooper R \& Korach KS 1998 Effects of castration and chronic steroid treatments on hypothalamic gonadotropin-releasing hormone content and pituitary gonadotropins in male wild-type and estrogen receptor- $\alpha$ knockout mice. Endocrinology 139 4092-4101. (doi:10.1210/en.139.10.4092)

Livak KJ \& Schmittgen TD 2001 Analysis of relative gene expression data using real-time quantitative PCR and the $2(-$ Delta Delta $C(T))$ method. Methods 25 402-408. (doi:10.1006/meth.2001.1262)

Lonnqvist F, Thorne A, Large V \& Arner P 1997 Sex differences in visceral fat lipolysis and metabolic complications of obesity. Arteriosclerosis, Thrombosis, and Vascular Biology 17 1472-1480.

Maier T, Guell M \& Serrano L 2009 Correlation of mRNA and protein in complex biological samples. FEBS Letters 583 3966-3973. (doi:10.1016/j. febslet.2009.10.036)

McGuire JJS, Hollis VW Jr \& Tomkins GM 1960 Some characteristics of the microsomal steroid reductases $(5 \alpha)$ of rat liver. Journal of Biological Chemistry 235 3112-3117.

Mendelson CR \& Kamat A 2007 Mechanisms in the regulation of aromatase in developing ovary and placenta. Journal of Steroid Biochemistry and Molecular Biology 106 62-70. (doi:10.1016/j.jsbmb.2007.05.001)

Miki H, Yamauchi T, Suzuki R, Komeda K, Tsuchida A, Kubota N, Terauchi Y, Kamon J, Kaburagi Y, Matsui J et al. 2001 Essential role of insulin receptor substrate 1 (IRS-1) and IRS-2 in adipocyte differentiation. Molecular and Cellular Biology 21 2521-2532. (doi:10.1128/ MCB.21.7.2521-2532.2001)
Pak TR, Chung WC, Lund TD, Hinds LR, Clay CM \& Handa RJ 2005 The androgen metabolite, $5 \alpha$-androstane- $3 \beta, 17 \beta$-diol, is a potent modulator of estrogen receptor- $\beta 1$-mediated gene transcription in neuronal cells. Endocrinology 146 147-155. (doi:10.1210/en.2004-0871)

Recabarren SE, Rojas-Garcia PP, Recabarren MP, Alfaro VH, Smith R, Padmanabhan V \& Sir-Petermann T 2008 Prenatal testosterone excess reduces sperm count and motility. Endocrinology 149 6444-6448. (doi:10. 1210/en.2008-0785)

Reiling BA, Drackley JK, Grum LR \& Berger LL 1997 Effects of prenatal androgenization and lactation on adipose tissue metabolism in finishing single-calf heifers. Journal of Animal Science 75 1504-1513.

Ronti T, Lupattelli G \& Mannarino E 2006 The endocrine function of adipose tissue: an update. Clinical Endocrinology 64 355-365. (doi:10.1111/j. 1365-2265.2006.02474.x)

Sam S, Legro RS, Bentley-Lewis R \& Dunaif A 2005 Dyslipidemia and metabolic syndrome in the sisters of women with polycystic ovary syndrome. Journal of Clinical Endocrinology and Metabolism 90 4797-4802. (doi:10.1210/jc.2004-2217)

Sam S, Legro RS, Essah PA, Apridonidze T \& Dunaif A 2006 Evidence for metabolic and reproductive phenotypes in mothers of women with polycystic ovary syndrome. PNAS 103 7030-7035. (doi:10.1073/pnas. 0602025103

Sam S, Coviello AD, Sung YA, Legro RS \& Dunaif A 2008 Metabolic phenotype in the brothers of women with polycystic ovary syndrome. Diabetes Care 31 1237-1241. (doi:10.2337/dc07-2190)

Sundaram SS, Whitington PF \& Green RM 2005 Steatohepatitis develops rapidly in transgenic mice overexpressing Abcb11 and fed a methionine-choline-deficient diet. American Journal of Physiology. Gastrointestinal and Liver Physiology 288 G1321-G1327. (doi:10.1152/ ajpgi.00455.2004)

Urbanek M 2007 The genetics of the polycystic ovary syndrome. Nature Clinical Practice. Endocrinology and Metabolism 3 103-111. (doi:10.1038/ ncpendmet0400)

Vague J 1956 The degree of masculine differentiation of obesities: a factor determining predisposition to diabetes, atherosclerosis, gout, and uric calculous disease. American Journal of Clinical Nutrition 4 20-34.

Weihua Z, Makela S, Andersson LC, Salmi S, Saji S, Webster JI, Jensen EV, Nilsson S, Warner M \& Gustafsson JA 2001 A role for estrogen receptor $\beta$ in the regulation of growth of the ventral prostate. PNAS 98 6330-6335. (doi:10.1073/pnas.111150898)

Wolf CJ, Hotchkiss A, Ostby JS, LeBlanc GA \& Gray LE Jr 2002 Effects of prenatal testosterone propionate on the sexual development of male and female rats: a dose-response study. Toxicological Sciences 65 71-86. (doi:10. 1093/toxsci/65.1.71)

Yildiz BO, Yarali H, Oguz H \& Bayraktar M 2003 Glucose intolerance, insulin resistance, and hyperandrogenemia in first degree relatives of women with polycystic ovary syndrome. Journal of Clinical Endocrinology and Metabolism 88 2031-2036. (doi:10.1210/jc.2002-021499)

Yilmaz M, Bukan N, Ersoy R, Karakoc A, Yetkin I, Ayvaz G, Cakir N \& Arslan M 2005 Glucose intolerance, insulin resistance and cardiovascular risk factors in first degree relatives of women with polycystic ovary syndrome. Human Reproduction 20 2414-2420. (doi:10.1093/humrep/ dei070)

Received in final form 16 November 2010 Accepted 20 December 2010 Made available online as an Accepted Preprint 20 December 2010 